large pieces of the station's backbone-like structure and more solar arrays for electrical power.

That schedule has now been scrapped. But if the shuttles are flying again within a few months, the station's research programme may not be greatly affected, says Milburn Jessup, a professor of oncology at the Georgetown University Medical Center in Washington DC and chairman of the space station scientific users' committee. Only one of next year's assembly flights was to involve Columbia, and NASA might well be able to use another vehicle in its place.

Delays beyond that could pose problems, particularly if the sequence in which research equipment is delivered to the station has to be rearranged, says Jessup. A lengthy delay, like the almost three-year downtime after the Challenger accident, could be devastating, forcing scientists to stop work on experimental equipment bound for the station.

NASA is under pressure to get the shuttles flying quickly. The station's current three-man crew can remain onboard at least until June, their time being limited by factors such as onboard supplies. If the shuttle is not cleared to fly by then, NASA could, in a worst case, be forced to power down the outpost and leave it abandoned until a new shuttle crew can be sent up.

Russian Soyuz craft are currently the only vehicles besides the shuttles that can ferry crews to the station. But the cashstrapped Russian government is barely able to produce the two vehicles a year required to fulfil its obligations to the international project. And US law bars NASA from buying more Soyuz vehicles from Russia, which it accuses of selling arms to unfriendly states.

Watching the situation warily are the station's partners from Europe, Japan and Canada. Even if the shuttles resume flying soon, NASA still has no short-term plan for a vehicle that could safely evacuate a crew of six or seven - the minimum number required to make full use of the laboratory, according to scientists. NASA's newly proposed Orbital Space Plane, designed to dock with the station after launching on a conventional rocket, could take up to ten years to design and build.

Critics of NASA, such as Congressman Ralph Hall (Democrat, Texas), the senior Democrat on the House Committee on Science, argue that this would be far too little, too late, to salvage the utility of the space station. As long as the crew 'lifeboat' issue remains unresolved, they charge, the station will be next to useless as a scientific laboratory - whether the shuttles are flying again or not.

\title{
Science had rare leading role in ill-starred shuttle mission
}

\section{David Adam}

The mission that tragically ended over Texas on 1 February was one of a vanishing breed - it was the first flight of the space shuttle in three years that was dedicated entirely to scientific research.

Columbia was carrying more than 80 separate experiments across the spectrum of science, from tests on the effects of microgravity on protein-crystal growth and ant behaviour, to orbital observations of dust blown from the Sahara Desert, which may affect weather and climate in other regions.

The mission also investigated the effects of space flight on astronauts' health. Some tests probed the cells that make up the immune system, and others examined ways to stop astronauts developing kidney stones. One experiment simply sought ways to help astronauts sleep more soundly.

These tests, like most of the rest of the mission's scientific payload, were led by NASA scientists. But a portion of the mission's scientific capability was handed over to paying customers, including the European and Canadian space agencies, who were each using the 16-day flight to analyse the effects of anti-osteoporosis drugs on bone cells in microgravity. The US Air Force also had a stake in the flight, testing communications technology that would identify enemy threats using miniature satellites. These experiments were held in a special pressurized research module - designed and built by Spacehab, a company based in Webster, Texas - in the shuttle's cargo bay.

The Israeli Space Agency, which sponsored the dust experiment, thinks that about $80 \%$ of the data from that experiment and the agency's other projects were beamed to Earth before the shuttle's demise. Those carrying out other tests, including some involving live animals, have lost their studies and may have to wait years for another opportunity.

The mission also marked an effort by NASA to capture the imagination of a younger generation. A set of experiments based on a menagerie of wildlife including bees, spiders, silkworms and fish embryos was being keenly monitored by pupils at schools in the United States, Australia, China, Israel, Japan and Liechtenstein. Other students in Germany handled the ground-based control experiment for separate space research into aquatic ecosystems (see Nature 421,307; 2003).

This geographical diversity was reflected in the mission's seven-strong crew. One, Ilan Ramon, was the first Israeli in space, and a second, Kalpana Chawla, hailed from India. The flight was Chawla's second trip on Columbia, having flown in 1997. Ramon, a former fighter

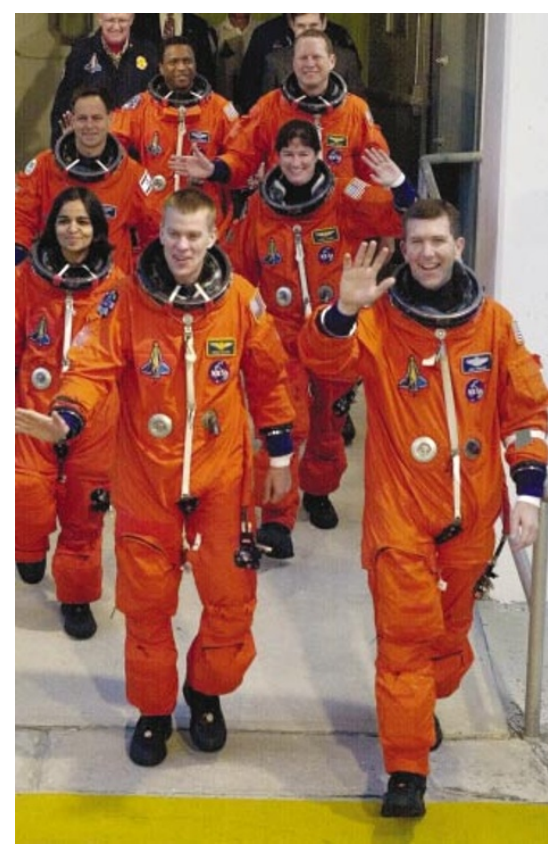

Columbia's crew addressed scientific issues ranging from astronaut health to climatology.

pilot who flew in Israel's 1981 mission to destroy a nuclear reactor being built in Iraq, attracted much of the pre-flight publicity, and ensured that security was beefed up.

Two of the other crew members had flown in space before. Rick Husband piloted the shuttle Discovery to the first docking with the International Space Station in 1999, and Michael Anderson was on Endeavour when it visited the Mir station in 1998. Of the astronauts making their maiden trips, two - David Brown and Laurel Clark - were physicians and the shuttle's pilot, William McCool, was a former US Navy test pilot.

Before the accident, questions had been asked about the scientific value of the mission's estimated US\$500-million price tag. Such conjecture will now be joined by more serious doubts over the human cost. Some researchers argue that unmanned probes can deliver better value; others insist that the challenge, daring and undoubted glamour of crewed missions bring less prosaic advantages.

Zev Levin at Tel Aviv University is one advocate of crewed research. As principal investigator of the Saharan dust experiment, Levin says that the flight captured the public imagination as an unmanned satellite never could. "In the past year I've spoken to students many times and you wouldn't believe the interest," he says. "Maybe some of them will go into science instead of becoming lawyers." Additional reporting by Haim Watzman, Jerusalem. 